\title{
Using Non-Covalent Complexes to Direct the Fragmentation of Glycosidic Bonds in the Gas Phase ${ }^{+}$
}

\author{
Ana K. Vrkic and Richard A. J. O'Hair \\ School of Chemistry, University of Melbourne, Parkville, Victoria, Australia
}

An investigation of the gas phase chemistry of proton bound oligosaccharide (S)-ligand (L) non-covalent complexes, $[\mathrm{S}+\mathrm{H}+\mathrm{L}]^{+}$has been carried out using electrospray ionization (ESI) and tandem mass spectrometry in a quadrupole ion trap. When subjected to collision-induced dissociation (CID), these $[\mathrm{S}+\mathrm{H}+\mathrm{L}]^{+}$complexes undergo a range of reactions that can be broadly classified into three main types: (1) Simple dissociation into the individual monomers; (2) cleavage of the oligosaccharide to form B-type sequence ions; (3) cleavage of the ligand species. The second type of reaction is particularly interesting as it can produce a "ladder series" of $\left[\mathrm{B}_{\mathrm{x}}+\mathrm{L}\right]^{+}$ions via ligand induced oligosaccharide bond cleavage. This novel gas phase reaction greatly simplifies the sequencing of oligosaccharides. Both the oligosaccharide and ligand were found to influence the type of reaction pathway observed, with the "ladder series" of $\left[\mathrm{B}_{\mathrm{x}}+\mathrm{L}\right]^{+}$ions being favored for permethylated oligosaccharides and for bifunctional ligands. Cytosine is a particularly good ligand at facilitating the formation of $\left[\mathrm{B}_{\mathrm{x}}+\mathrm{L}\right]^{+}$ions. Analogies with condensed phase chemistry of sugars is made and a potential mechanism for ligand induced oligosaccharide bond cleavage is proposed. (J Am Soc Mass Spectrom 2004, 15, 715-724) (c 2004 American Society for Mass Spectrometry

$\mathrm{M}$ ass spectrometry (MS) has become an important analytical tool for the examination of non-covalent interactions of biological interest due to the coupling of soft ionization modes [such as electrospray ionization (ESI) and matrix assisted laser desorption ionization, (MALDI)] with the inherent four "S" advantages of MS: Specificity, sensitivity, speed, and stoichiometry [1]. Chemists have also been intrigued by the possibility of examining the fundamental properties (structure and reactivity) of these complexes, giving birth to the new area of gas phase molecular recognition and supramolecular chemistry [2]. Various tandem mass spectrometry (MS/MS) techniques such as collision induced dissociation (CID) and ion-mole- cule reactions have provided insights into the gas phase chemistry of non-covalent complexes. Some non-covalent complexes fail to simply dissociate to their monomers under MS/MS conditions and instead undergo remarkable alternative fragmentation reactions. For example, in the gas phase, double stranded DNA fragments via loss of nucleobases (i.e., breaking of covalent bonds) rather than forming the single stranded DNA monomer (i.e., breaking of non-covalent bonds) [3]. More recently, three groups have observed that phosphate anions of biological interest undergo condensation reactions that involve diphosphate formation (eq 2) [4] or triphosphate formation [4] reactions that are in competition with monomer formation (eq 1).

$$
\begin{aligned}
\mathrm{HO}(\mathrm{XO}) \mathrm{PO}_{2}^{\ominus}\left((\mathrm{HO})_{2}(\mathrm{YO}) \mathrm{PO}\right)- & \mathrm{HO}(\mathrm{XO}) \mathrm{PO}_{2}^{\ominus}+(\mathrm{HO})_{2}(\mathrm{YO}) \mathrm{PO} \\
\rightarrow & \mathrm{HO}(\mathrm{YO}) \mathrm{PO}_{2}^{\ominus}+(\mathrm{HO})_{2}(\mathrm{XO}) \mathrm{PO} \\
\rightarrow & \mathrm{HO}(\mathrm{YO}) \mathrm{OPOPOP}(\mathrm{OH}) \mathrm{O}_{2}^{\ominus}+\mathrm{YOH} \\
& \mathrm{HH}) \mathrm{O}_{2}^{\ominus}+\mathrm{XOH}
\end{aligned}
$$

Published online March 2, 2004

Address reprint requests to Dr. R. A. J. O'Hair, School of Chemistry, University of Melbourne, Parkville, Victoria 3010, Australia. E-mail: rohair@unimelb.edu.au

${ }^{+}$Gas Phase Ion Chemistry of Biomolecules, Part 39.
In a recent study, we noted that $\beta$-cyclodextrin: nucleobase non-covalent complexes undergo novel cleavage of sugar units of the $\beta$-cyclodextrin host, with retention of the guest [5]. We suggested that a guest- 


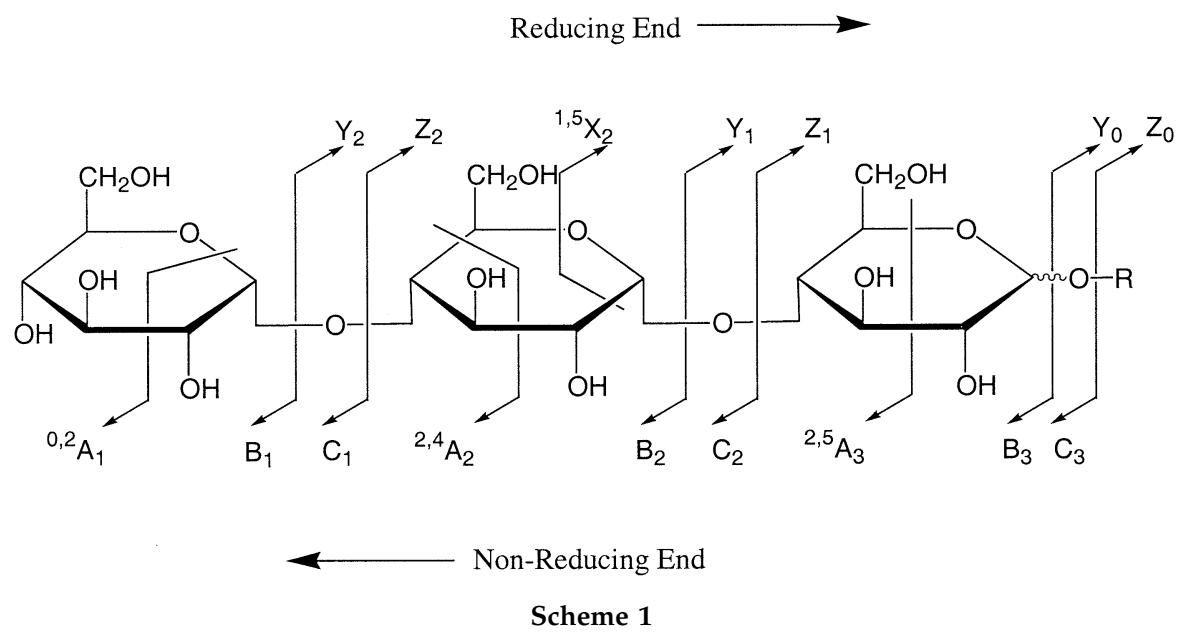

induced ring opening reaction mechanism preceded sugar loss, and observed that a bifunctional guest was required. Such a bifunctional guest can potentially offer combined acid and base catalysis for glycosidic bond cleavage. During the course of our work, Von Seggern and Cotter have reported that non-covalent sugarsugar complexes also undergo sugar fragmentation and rearrangement before complex breakdown, although they did not offer mechanistic insights into these processes [6]. Anionic complexes between chloride ions and oligosaccharides also appear to facilitate cleavage of saccharide bonds [7]. In this paper, we examine the CID fragmentation pathways of proton bound noncovalent complexes between linear sugars and nucleobases and related compounds to see if we can direct the fragmentation of glycosidic bonds.

\section{Experimental}

\section{Materials}

All nucleobases (adenine, cytosine, guanine, thymine), nucleosides (2'-deoxyadenosine, 2'-deoxycytidine, 2'deoxyguanosine, $2^{\prime}$-deoxythymidine, and oligosaccharides (maltose, maltotriose, maltotetraose, maltopentaose, maltohexaose) were obtained from Sigma Chemical Co. (St. Louis, MO) and used without further purification. Permethylated oligosaccharides were synthesized via the method described by Ciucanu and Kerek [8].

\section{Quadrupole Ion Trap Mass Spectrometry Experiments}

All experiments were performed using a commercially available quadrupole ion trap mass spectrometer (Finnigan-MAT model LCQ, San Jose, CA) equipped with electrospray ionization (ESI) [9]. A 1:1 mixture of the oligosaccharide and nucleobase/nucleoside was dissolved in a 50:50 mixture of $\mathrm{H}_{2} \mathrm{O}$ and $\mathrm{CH}_{3} \mathrm{OH}(1 \%$ acetic acid) $(0.1 \mathrm{mg} / \mathrm{mL})$ and introduced to the mass spectrometer at $3.0 \mu \mathrm{L} / \mathrm{min}$ via electrospray ionization. Typical ESI conditions used were: spray voltage, 4.0$4.5 \mathrm{kV}$, capillary temperature, $200{ }^{\circ} \mathrm{C}$, nitrogen sheath pressure, $40 \mathrm{psi}$, and capillary voltage/tube lens offset, 0-10 V. Collision induced dissociation (CID) of the inclusion complexes was carried out by mass selecting the desired ions with a 5-10 Th window and subjecting them to the following typical conditions: activation amplitude, $0.7-1.5 \mathrm{~V}$; activation $(\mathrm{Q}), 0.25 \mathrm{~V}$, and activation time $100 \mathrm{~ms}$.

\section{Results and Discussion}

The widespread use of tandem mass spectrometry for the sequencing of biopolymers has resulted in an accepted nomenclature for sequence ions derived from peptides [10], oligonucleotides [11] and oligosaccharides (illustrated for a trisaccharide in Scheme 1) [12]. For example, oligosaccharide sequence ions that retain the charge at the reducing terminus are designated $X, Y$ and $\mathrm{Z}$ ions, whereas the complementary sequence ions that retain the charge at the non-reducing terminus are designated as $\mathrm{A}, \mathrm{B}$, and $\mathrm{C}$ ions. The differentiation between $\mathrm{A}, \mathrm{B}$, and $\mathrm{C}$ or $\mathrm{X}, \mathrm{Y}$, and $\mathrm{Z}$ ions reflects the different bonds being broken in the oligosaccharide.

\section{Changing the Identity of the Charge Donor Influences the CID Fragmentation Reactions of Oligosaccharides}

A considerable amount of effort has been invested into understanding the mechanisms and factors that influence the fragmentation reactions of ions derived from biopolymers [13-15]. It has emerged that the identity of the charge donor can have an important effect on the fragmentation reactions observed. For example, $[\mathrm{M}+\mathrm{H}]^{+},[\mathrm{M}+\mathrm{Li}]^{+}$and $[\mathrm{M}-\mathrm{H}]^{-}$ions of peptides fragment differently and can thus provide complementary structural information, while recent work on the fragmentation reactions of radical cations of pep- 


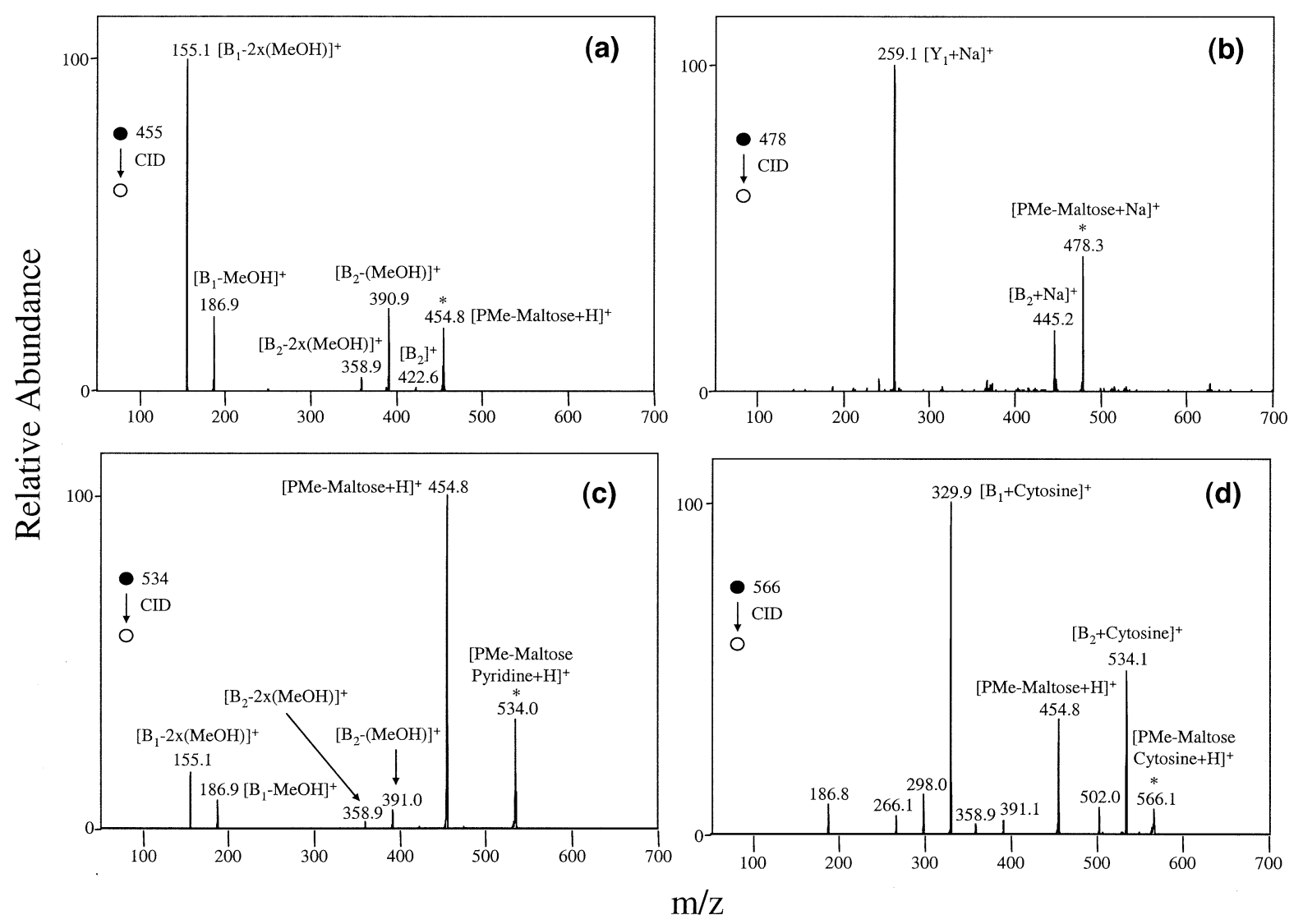

Figure 1. LCQ CID spectra of: (a) [PMe-maltose $+\mathrm{H}^{+}$; (b) $[\mathrm{PMe}-\text { maltose }+\mathrm{Na}]^{+}$; (c) $[\mathrm{PMe}-\mathrm{Paltose}$ + pyridine $+\mathrm{H}]^{+} ;\left(\right.$d) $[\mathrm{PMe}-\text { maltose }+ \text { cytosine }+\mathrm{H}]^{+}$.

tides shows that the radical site can direct fragmentation [16]. The same holds true for oligosaccharidestwo recent independent studies have shown that $[\mathrm{M}+$ $\mathrm{H}]^{+}$ions of derivatized oligosaccharides can undergo rearrangement reactions, while the corresponding $[\mathrm{M}+$ $\mathrm{Na}]^{+}$do not [17].

Figure 1 confirms that the nature of the charge donor does influence the types of fragmentation reactions observed for a simple oligosaccharide. The permethylated maltose disaccharide provides a convenient model as it readily forms a range of different types of ions under ESI/MS conditions including protonated, sodiated, and non-covalent complexes. CID of the protonated disaccharide provides $\left[\mathrm{B}_{\mathrm{n}}\right]^{+}$sequence ions, including those that have undergone subsequent methanol loss to form $\left[\mathrm{B}_{\mathrm{n}}-\mathrm{xMeOH}\right]^{+}$ions (Figure 1a). Mendonca et al. have suggested that the reason why ions such as $\left[\mathrm{B}_{1}-2 \mathrm{MeOH}\right]^{+}$are abundant fragment ions is that they have the Structure A shown below, which is stabilized by aromaticity [18]. In contrast, the sodium prefers to reside on the reducing end of the sugar, and the $\left[\mathrm{Y}_{1}+\mathrm{Na}\right]^{+}$, becomes the most abundant product ion in the CID spectrum of the [PMe-maltose $+\mathrm{Na}]^{+}$ (Figure $1 \mathrm{~b}$ ), while the $\left[\mathrm{B}_{2}+\mathrm{Na}\right]^{+}$is only a minor product. Our previous study on the fragmentation reactions of host-guest complexes revealed that the guest can induce fragmentation of the oligosaccharide bonds of the host [5]. To investigate whether related reactions occur for permethylated maltose, $\mathrm{S}$, we have examined the fragmentation reactions of its proton bound non-covalent complexes with a number of ligands, L, including those with pyridine (Figure 1c) and cytosine (Figure 1d). A comparison of these two spectra reveals that the ligand, $\mathrm{L}$, plays an important role in directing the fragmentation reactions of the $[\mathrm{S}+\mathrm{H}+$ $\mathrm{L}^{+}$non-covalent complex, consistent with our previous study [5]. Thus pyridine, which bears a sole functional group, undergoes neutral ligand loss to form the protonated permethylated maltose at $\mathrm{m} / \mathrm{z} 454.8$ (Figure 1c), which undergoes subsequent fragmentation reactions to yield similar sequence ions to those formed via direct CID on protonated permethylated maltose (Figure 1a). In contrast, the cytosine ligand directs cleavage of the oligosaccharide bonds to yield the novel $\left[B_{x}+L\right]^{+}$ sequence ions (Figure 1d). Simple neutral ligand loss to form the protonated permethylated maltose at $\mathrm{m} / \mathrm{z} 454.8$ is attenuated, as are its subsequent fragmentation products. Thus, the presence of multiple functional groups within the cytosine ligand appears to help facilitate the formation of $\left[\mathrm{B}_{\mathrm{x}}+\mathrm{L}\right]^{+}$sequence ions.

In order to further examine the formation of these ions, we decided to thoroughly investigate the role of 


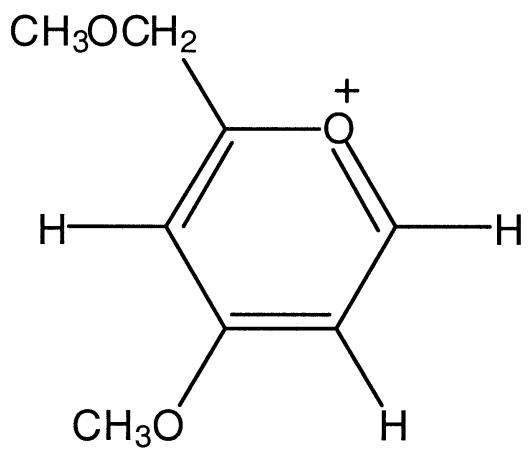

A

each of the partners in the proton bound $\left[\mathrm{S}+\mathrm{H}+\mathrm{L}^{+}\right.$ non-covalent complexes. Thus, we have varied the structure of the sugar, S, not only by changing its size (from a disaccharide through to a hexasaccharide) but also by examining the role of methylation (i.e., comparing the native, non-methylated saccharide to its permethylated counterpart). In addition, we have examined a range of ligands, $\mathrm{L}$, in order to determine the structural motifs required to "switch on" the formation of the novel $\left[\mathrm{B}_{\mathrm{x}}+\mathrm{L}\right]^{+}$sequence ions. The results of these studies are described in the next sections.
Summary of the CID Fragmentation Reaction Pathways of Non-Covalent Oligosaccharide-Ligand Complexes

By varying (1) the sugar, $S$, to include permethylated and native oligosaccharides and (2) the ligand to include nucleobases, nucleosides and structurally related pyridines, a total of 130 tandem mass spectra were examined to determine the structural motifs required to "switch on" the formation of the novel $\left[\mathrm{B}_{\mathrm{x}}+\mathrm{L}\right]^{+}$ sequence ions. While each of the mass spectra are available from the authors upon request, Tables 1 and 2 summarize the primary CID fragmentation pathways of the various permethylated and native oligosaccharideligand complexes, respectively. Under these conditions, the complexes undergo a range of reactions, which can be broadly classified into the following types: (1) Simple dissociation of the complex into its monomeric constituents; (2) cleavage of covalent bonds within the oligosaccharide; (3) cleavage of covalent bonds within the ligand. These reactions are represented in a simplified cartoon form in Scheme 2. Overall, the fragmentation reactions of these oligosaccharide-ligand complexes are quite diverse and do indeed depend upon the structures of both the oligosaccharide and the ligand. Thus, product ions corresponding to the simple loss of the ligand, with either charge retention by the oligosaccharide (Path $1 \mathrm{~A}$, Scheme 2) or by the ligand (Path 1B, Scheme 2) were observed. Cleavage of the oligosaccha-

Table 1. Summary of the main CID fragmentation pathways of the permethylated oligosaccharide non-covalent complexes in the ion trap

\begin{tabular}{|c|c|c|c|c|c|c|c|c|c|c|}
\hline \multirow[b]{3}{*}{ Guest Species } & \multicolumn{10}{|c|}{ CID reaction pathway } \\
\hline & \multicolumn{2}{|c|}{ PMe-maltose } & \multicolumn{2}{|c|}{ PMe-maltotriose } & \multicolumn{2}{|c|}{$\begin{array}{c}\text { PMe- } \\
\text { maltotetraose }\end{array}$} & \multicolumn{2}{|c|}{$\begin{array}{c}\text { PMe- } \\
\text { maltopentaose }\end{array}$} & \multicolumn{2}{|c|}{$\begin{array}{c}\text { PMe- } \\
\text { maltohexaose }\end{array}$} \\
\hline & Major & Minor & Major & Minor & Major & Minor & Major & Minor & Major & Minor \\
\hline Adenine & $1 \mathrm{a}^{\mathrm{a}}$ & $2 a^{a}$ & $2 a$ & $1 \mathrm{a}$ & $2 a$ & & $2 a$ & & $2 a$ & \\
\hline Cytosine & $2 a^{b}$ & $1 a^{b}$ & $2 a^{d}$ & & $2 a^{e}$ & & $2 a^{f}$ & & $2 a^{g}$ & \\
\hline Guanine & $2 a$ & $1 a$ & $2 a$ & & $2 a$ & & $2 a$ & & $2 a$ & \\
\hline Thymine & $1 a$ & & $1 \mathrm{a}$ & & $1 \mathrm{a}$ & & $1 a$ & & $1 a$ & \\
\hline Deoxyadenosine & $1 b$ & & $\begin{array}{l}2 a \\
3\end{array}$ & $1 \mathrm{a}$ & $\begin{array}{l}2 a \\
3\end{array}$ & & 3 & $2 a$ & 3 & $2 a$ \\
\hline Deoxycytidine & $1 b$ & & 3 & $2 a$ & 3 & $2 a$ & 3 & $2 a$ & 3 & $2 a$ \\
\hline Deoxyguanosine & $1 b$ & & $\begin{array}{l}1 \mathrm{~b}, \\
3\end{array}$ & $2 a$ & 3 & $2 a$ & 3 & $2 a$ & 3 & $2 a$ \\
\hline Deoxythymidine & $2 a$ & & $1 \mathrm{a}$ & & $1 \mathrm{a}$ & & 3 & $1 \mathrm{a}$ & $1 \mathrm{a}$ & 3 \\
\hline Pyridine & $1 a^{c}$ & & $1 \mathrm{a}$ & & $1 \mathrm{a}$ & $2 a$ & $1 a$ & & $1 \mathrm{a}$ & \\
\hline 2-Hydroxypyridine & $1 \mathrm{a}$ & & $1 \mathrm{a}$ & $2 a$ & $1 \mathrm{a}$ & & $1 a$ & $2 a$ & $1 a$ & \\
\hline 2-Aminopyridine & $1 \mathrm{a}$ & & $2 a$ & $1 \mathrm{a}$ & $2 a$ & & $2 a$ & $1 \mathrm{a}$ & $2 a$ & $1 \mathrm{a}$ \\
\hline 3-Aminopyridine & $1 a$ & & $1 \mathrm{a}$ & $2 a$ & $2 a$ & $1 a$ & $2 a$ & $1 a$ & $2 a$ & $1 a$ \\
\hline 4-Aminopyridine & $1 \mathrm{a}$ & & $1 a$ & & $1 a$ & & $2 a$ & & $2 a$ & \\
\hline
\end{tabular}

Note: $1 \mathrm{a}=$ loss of ligand, with charge on oligosaccharide; $1 \mathrm{~b}=$ loss of ligand, with charge on ligand; $2 \mathrm{a}=\left[\mathrm{B}_{\mathrm{x}}+\mathrm{Nu}\right]^{+}$formation; $3=$ cleavage of ligand.

${ }^{a}$ See Figure 2a.

${ }^{b}$ See Figure 1d.

'See Figure 1c.

${ }^{\mathrm{d}}$ See Figure $3 \mathrm{a}$.

See Figure 3b.

fSee Figure 3c.

9See Figure 3d. 
Table 2. Summary of the main CID fragmentation pathways of the native oligosaccharide non-covalent complexes in the ion trap

\begin{tabular}{|c|c|c|c|c|c|c|c|c|c|c|}
\hline \multirow[b]{3}{*}{ Guest Species } & \multicolumn{10}{|c|}{ CID Reaction Pathway } \\
\hline & \multicolumn{2}{|c|}{ Maltose } & \multicolumn{2}{|c|}{ Maltotriose } & \multicolumn{2}{|c|}{ Maltotetraose } & \multicolumn{2}{|c|}{ Maltopentaose } & \multicolumn{2}{|c|}{ Maltohexaose } \\
\hline & Major & Minor & Major & Minor & Major & Minor & Major & Minor & Major & Minor \\
\hline Adenine & $1 b^{a}$ & & $2 b$ & $1 \mathrm{a}$ & $2 b$ & $1 \mathrm{a}$ & $1 \mathrm{a}$ & $2 b$ & $2 b$ & $1 \mathrm{a}$ \\
\hline Cytosine & $2 a$ & $1 \mathrm{a}$ & $2 a$ & $1 a, 2 b$ & $2 a, 2 b$ & $1 \mathrm{a}$ & $2 b$ & $1 \mathrm{a}, 2 \mathrm{a}$ & $2 b$ & $1 \mathrm{a}, 2 \mathrm{a}$ \\
\hline Guanine & $1 \mathrm{~b}$ & & $2 a$ & & $2 a$ & & $2 \mathrm{~b}$ & $1 a, 2 a$ & $2 b$ & $1 a, 2 a$ \\
\hline Thymine & $2 a$ & $1 a, 2 b$ & $2 a$ & & $2 a$ & $1 a, 2 b$ & $1 \mathrm{a}$ & $2 a, 2 b$ & $1 \mathrm{a}$ & $2 a, 2 b$ \\
\hline Deoxyadenosine & $1 b$ & & $1 b$ & & $1 a, 2 b$ & $2 a, 3$ & $1 \mathrm{a}$ & $2 b, 3$ & $1 \mathrm{a}$ & $2 b, 3$ \\
\hline Deoxycytidine & $1 b$ & & $1 b$ & & 3 & $1 a, 2 b$ & 3 & $1 a, 2 b$ & 3 & $1 a, 2 b$ \\
\hline Deoxyguanosine & $1 b$ & & $1 b$ & & $1 b$ & 3 & 3 & $1 \mathrm{a}$ & 3 & $1 a, 2 b$ \\
\hline Deoxythymidine & $1 b$ & $2 a$ & $2 b$ & $1 a, 1 b, 2 a$ & $1 a$ & $2 b$ & $1 \mathrm{a}$ & $2 a, 2 b, 3$ & $1 \mathrm{a}$ & $2 a, 2 b$ \\
\hline Pyridine & $2 a$ & $1 a, 2 b$ & $2 b$ & $1 a$ & $1 a$ & $2 b$ & $1 a$ & & $1 \mathrm{a}$ & \\
\hline 2-Hydroxypyridine & $1 a, 2 a$ & $2 b$ & $2 b$ & $1 a, 2 a$ & $1 \mathrm{a}$ & $2 b$ & $1 \mathrm{a}$ & $2 b$ & $1 \mathrm{a}$ & \\
\hline 2-Aminopyridine & $1 \mathrm{a}$ & $2 a, 2 b$ & $2 b$ & $1 \mathrm{a}$ & $2 b$ & $1 \mathrm{a}$ & $1 a$ & $2 b$ & $1 a, 2 b$ & \\
\hline 3-Aminopyridine & $1 \mathrm{a}$ & $2 a$ & $2 b$ & $1 \mathrm{a}$ & $1 a$ & $2 b$ & $1 \mathrm{a}$ & $2 b$ & $1 \mathrm{a}$ & $2 b$ \\
\hline 4-Aminopyridine & $1 \mathrm{a}$ & $2 a$ & $2 b$ & $1 a, 2 a$ & $1 a$ & $2 b$ & $1 \mathrm{a}$ & $2 b$ & $1 \mathrm{a}$ & $2 b$ \\
\hline
\end{tabular}

Note: $1 a=$ loss of ligand, with charge on oligosaccharide; $1 b=$ loss of ligand, with charge on ligand; $2 a=\left[B_{x}+N u\right]^{+}$formation; $2 b=B_{x}$ formation following loss of ligand; 3 = cleavage of ligand.

${ }^{a}$ See Figure $2 b$.

ride with retention (i.e., $\left[\mathrm{B}_{\mathrm{x}}+\mathrm{L}\right]^{+}$) (Path $2 \mathrm{~A}$, Scheme 2 ) or loss (i.e., $\left[\mathrm{B}_{\mathrm{x}}\right]^{+}$) (Path $2 \mathrm{~B}$, Scheme 2 ) of the Ligand species were also observed. The final reaction pathway involved selective fragmentation and loss of part of the ligand, with the remainder of the complex staying intact (Path 3, Scheme 2).

Based on Cooks' kinetic method [19], the relative abundances of the ligand loss fragmentation pathways (Path $1 \mathrm{~A}$ versus Path $1 \mathrm{~B}$, Scheme 2 ) should reflect the relative gas phase basicities of the sugar and the ligand. We note that Cai and Cole have adopted a similar approach to determining the gas phase acidity of $\alpha$-Dglucose by examining the fragmentation reactions of its anionic non-covalent complexes [20]. While the careful evaluation of the gas phase basicities and proton affinities of oligosaccharides was not the aim of this work, a rigorous full-entropy kinetic method analysis [19] of proton bound dimers of oligosaccharides might provide such data, thereby alleviating the dearth of information on the gas phase basicities sugars [21]. Note that any kinetic method determination of the gas phase basicities and proton affinities of oligosachharides using related

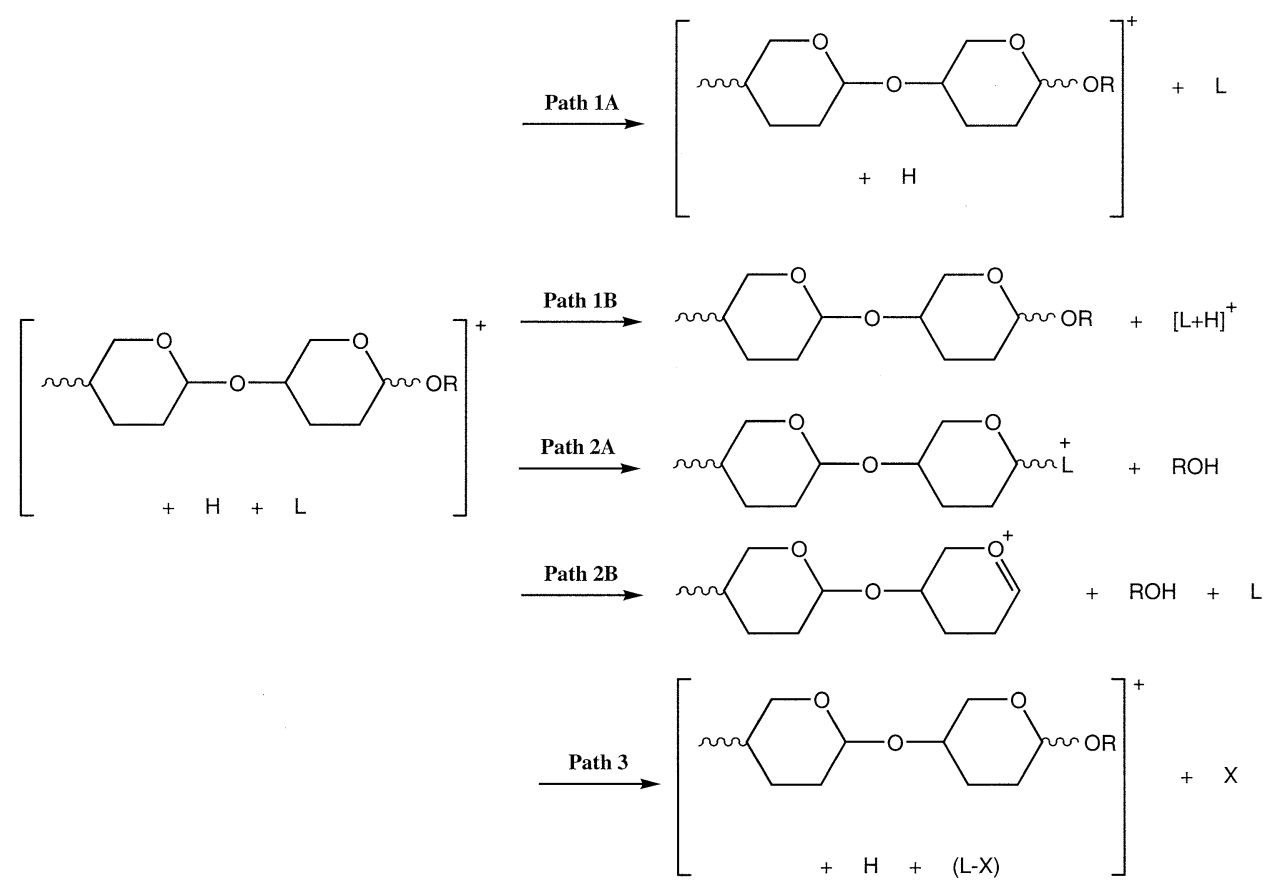

Scheme 2 


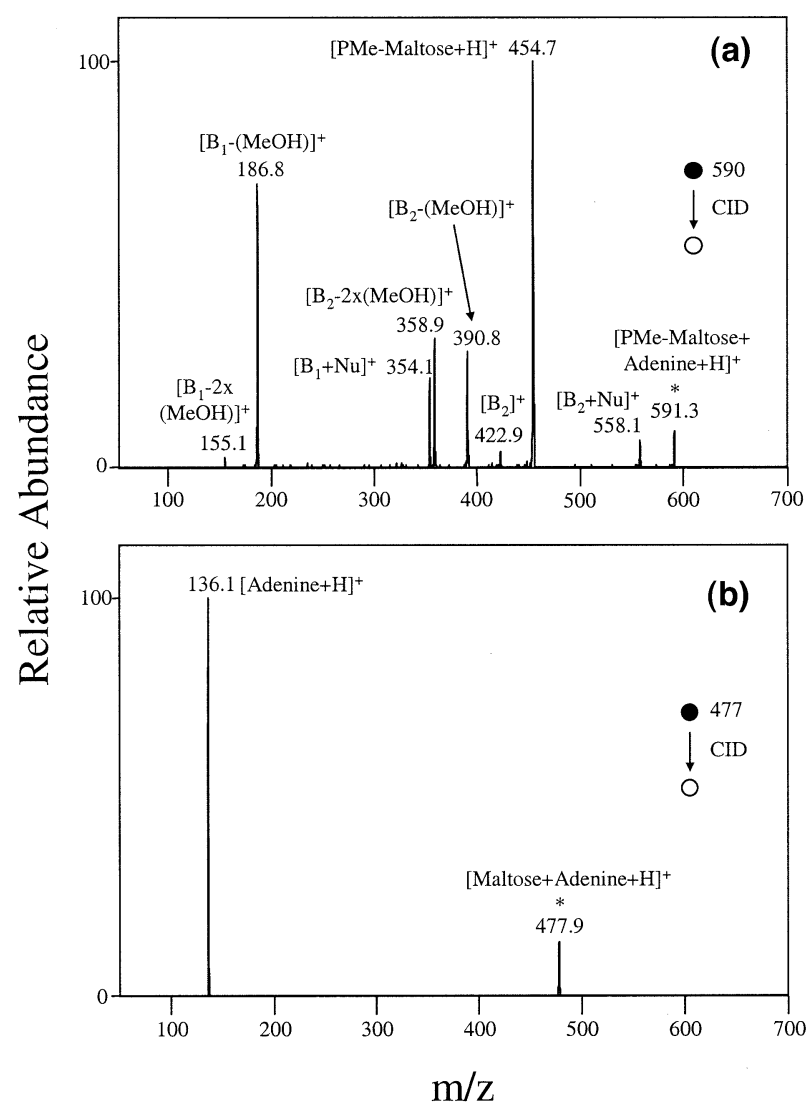

Figure 2. LCQ CID spectra of: (a) [PMe-maltose + adenine + $\mathrm{H}^{+}$; (b) [maltose + adenine $\left.+\mathrm{H}\right]^{+}$.

non-covalent complexes would also need to ensure that all caveats are heeded [19] including the assumption that isomeric forms of the activated cluster ion are absent and that consecutive decompositions of the implicated species do not take place. Given the rich other chemistry observed for many of the non-covalent complexes (Paths 2 and 3B, Scheme 2), neither of these requirements is assured in these systems.

\section{Role of the Oligosaccharide Species in Directing CID Fragmentation Reactions of Non-Covalent Oligosaccharide-Ligand Complexes}

A representative example illustrating the differences in reactivity between the permethylated and native systems is shown in Figure 2. Upon CID of [PMe-maltose + adenine $+\mathrm{H}^{+}$(Figure 2a), loss of the ligand yields the most abundant product ion, i.e., [PMe-maltose + $\mathrm{H}^{+}{ }^{+}(\mathrm{m} / \mathrm{z}$ 455) (Path 1A, Scheme 2). We also see the formation of the novel $\left[\mathrm{B}_{1}+\text { adenine }\right]^{+}\left(\mathrm{m} / z\right.$ 354) and $\left[\mathrm{B}_{2}\right.$ + adenine $^{+}(m / z 558)$ sequence ions (Path 2A, Scheme 2). In contrast to this, $\mathrm{CID}$ of [maltose + adenine $+\mathrm{H}]^{+}$ (Figure $2 \mathrm{~b}$ ) yields a much less complicated spectra, in which loss of the ligand results in formation of the [adenine $+\mathrm{H}]^{+}$ion (Path 1B, Scheme 2). These results imply that adenine is a stronger base than maltose, and that permethylated maltose is a stronger base than maltose (since proton transfer to the sugar becomes competitive). Due to the low mass cutoff of the LCQ, we cannot comment on the relative gas phase basicites of adenine and permethylated maltose.

Table 1 reveals that for the smaller permethylated oligosaccharide-ligand complexes (such as PMe-maltose-ligand), dissociation of the ligand species (either Path $1 \mathrm{~A}$ or $1 \mathrm{~B}$, Scheme 2 ) is most prevalent. We do however, also see the emergence of product ions corresponding to the formation of novel $\left[\mathrm{B}_{\mathrm{x}}+\mathrm{L}\right]^{+}$sequencetype ions (where ligand = adenine, cytosine, guanine, and dT) (Path 2A, Scheme 2). These ions are consistent with cleavage of the oligosaccharide with retention of the ligand. We note that as the size of the oligosaccharide species increases, formation of the $\left[\mathrm{B}_{\mathrm{x}}+\mathrm{L}\right]^{+}$ions becomes the main fragmentation pathway for many of the complexes. This observation appears to offer evidence that a ligand-to-oligosaccharide proton transfer reaction is occurring whereby the oligosaccharide effectively competes for the proton within the complex. Furthermore, it suggests that the proton is not limited to residing in one position, but actually "roams" around to other glycosidic bonds within the oligosaccharide. A possible mechanism for the above fragmentation will be discussed later.

Table 2 shows the reaction pathways of native oligosaccharide-ligand complexes are quite different when compared to their permethylated counterparts. It is interesting to note that dissociation of the ligand species (Paths 1A and IB, Scheme 2) is one of the major reaction pathways for all of the complexes listed in Table 2. In Table 1, however, $\left[B_{x}+L\right]^{+}$formation (Path 2A, Scheme 2) was observed to be the main fragmentation pathway for many of the permethylated systems.

For the majority of the larger native oligosaccharideligand complexes, dissociation of the ligand species was subsequently followed by cleavage of glycosidic bonds to yield $\left[\mathrm{B}_{\mathrm{x}}\right]^{+}$ions. These product ions were generally the most dominant peaks in the spectra. The formation of $\left[\mathrm{B}_{\mathrm{x}}+\mathrm{L}\right]^{+}$ions occurred only in some of the complexes and in relatively minor amounts.

\section{Role of the Ligand in Directing CID Fragmentation Reactions of Non-Covalent Oligosaccharide-Ligand Complexes}

In this study, three main types of "ligand" species were employed: (1) Nucleobases (i.e., adenine, cytosine, guanine, and thymine); (2) nucleosides (i.e., deoxyadenosine, deoxycytidine, deoxyguanosine, and deoxythymidine); (3) structurally related pyridines. We will first discuss the gas-phase fragmentation reactions of the permethylated complexes and then compare them with their native counterparts.

If we turn our attention back to Table 1, we can clearly see there are correlations between the type of ligand species utilized and the fragmentation behavior 


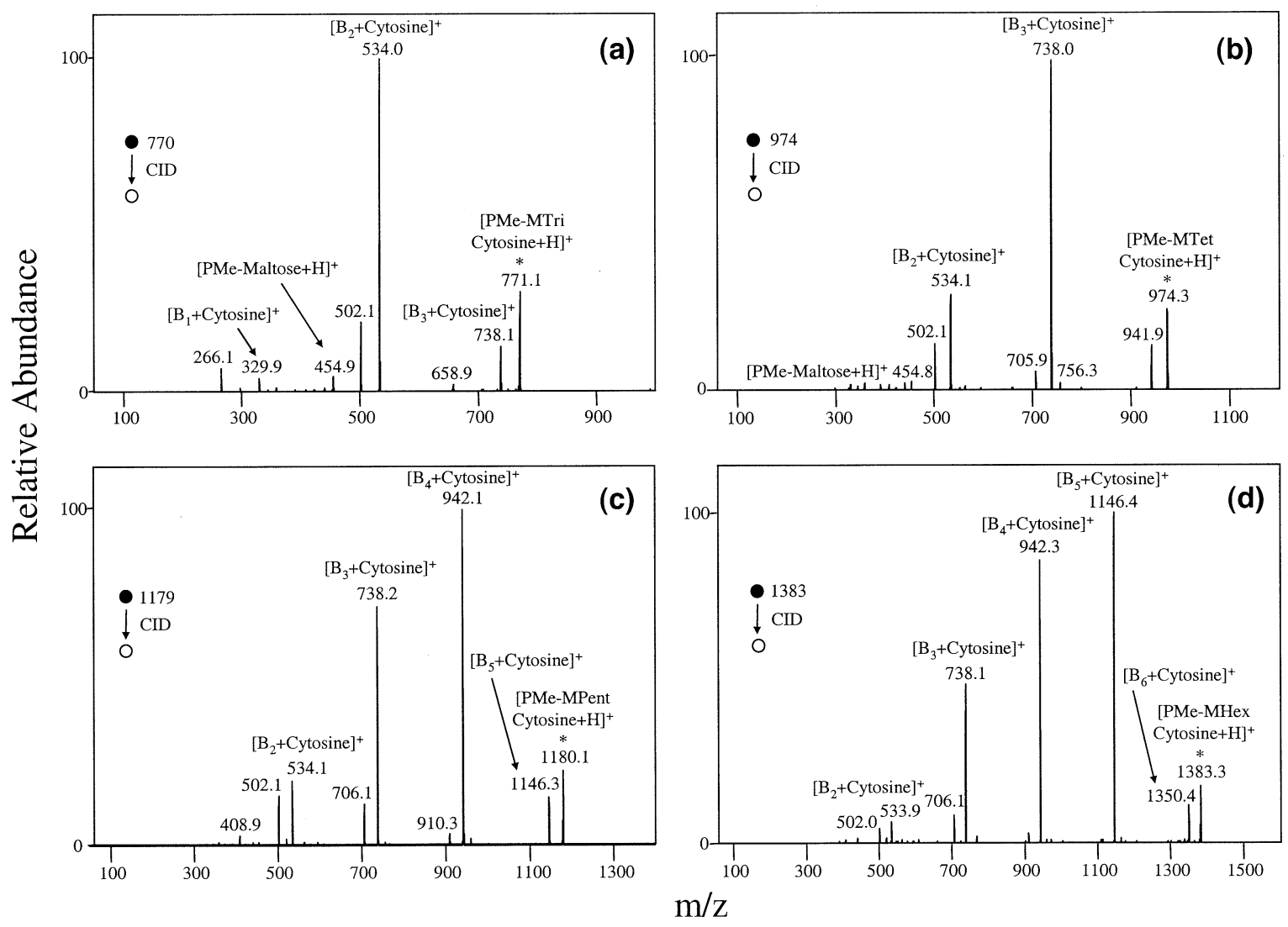

Figure 3. LCQ CID spectra of: (a) $[\mathrm{PMe}-\text { maltotriose }+ \text { cytosine }+\mathrm{H}]^{+} ;(\mathbf{b})[\mathrm{PMe}-$ maltotetraose + cytosine $+\mathrm{H}]^{+}$; (c) $\left[\right.$PMe-maltopentaose + cytosine $+\mathrm{H}^{+}$; (d) $[\text {PMe-maltohexaose }+ \text { cytosine }+\mathrm{H}]^{+}$.

of the non-covalent complexes. Thus, CID of [S + H + $\mathrm{L}^{+}$(where $\mathrm{L}=$ adenine, cytosine, and guanine) were all observed to fragment via the loss of a saccharide residues (whilst retaining the ligand species) to yield $\left[\mathrm{B}_{\mathrm{x}}+\mathrm{L}\right]^{+}$ions (Path 2A, Scheme 2). A representative example of this type of fragmentation behavior is shown in Figure $1 \mathrm{~d}$ for [PMe-maltose + cytosine $+\mathrm{H}]^{+}$. Upon CID of this complex, we clearly observe $\left[\mathrm{B}_{1}+\right.$ cytosine ${ }^{+}(\mathrm{m} / \mathrm{z} 330)$ and $\left[\mathrm{B}_{2}+\text { cytosine }\right]^{+}(\mathrm{m} / \mathrm{z} 534)$ to be the most abundant product ions. In contrast to this, the [PMe-oligosaccharide + thymine $+\mathrm{H}]^{+}$systems all resulted in dissociation of thymine (Path 1A, Scheme 2).

Another fragmentation pathway occurs for some ligands and involves cleavage of a covalent bond of the ligand (Path 3, Scheme 2). This type of fragmentation occurs for the majority of the oligosaccharide-nucleoside complexes in which pyranose sugar loss from the nucleoside generates a new oligosaccharide-nucleobase non-covalent complex. This cleavage of the N-glycosidic bond in the nucleoside (and subsequent sugar loss) was the main fragmentation pathway for those complexes generally containing: (1) Deoxycytidine and deoxyguanosine and (2) larger host oligosaccharides (ranging from [PMe-maltotriose] to [PMe-maltohexaose]). In contrast, loss of the intact ligand species occurred for the smaller complexes (such as [PMe- maltose + nucleoside $+\mathrm{H}]^{+}$, where nucleoside $=$ adenine, cytosine, and guanine) (Path 1B, Scheme 2).

The final set of ligand species utilized involved pyridines that were structurally related to the nucleobases. We decided to look at a range of ligand species which mimicked particular aspects of the nucleobases in order to ascertain what made these non-covalent permethylated oligosaccharide-ligand complexes prone to fragmentation via Path 2A, Scheme 2. For [PMeoligosaccharide + ligand $+\mathrm{H}^{+}$(where ligand $=$pyridine and 2-hydroxypyridine) dissociation of the ligand species was observed to be the main reaction pathway (Path 1A, Scheme 2). This type of behavior is illustrated in Figure 1c for [PMe-maltose + pyridine $+\mathrm{H}]^{+}$. CID of this complex resulted in formation of [PMe-maltose + $\mathrm{H}^{+}$at $m / z$ 455. In the case of [PMe-oligosaccharide + ligand $+\mathrm{H}^{+}$(where ligand $=2,3$, and 4 aminopyridine) there were two types of reaction pathways, i.e., (1) dissociation of the ligand species for the smaller complexes (Path 1A, Scheme 2); (2) cleavage of the oligosaccaharide with retention of the ligand for the larger complexes (Path 2A, Scheme 2). Thus, these results appear to suggest that the amino group on the nucleobases plays an integral role in assisting the complexes to fragment via Path 2A, Scheme 2.

Examination of Table 2 shows correlations between 
(a)
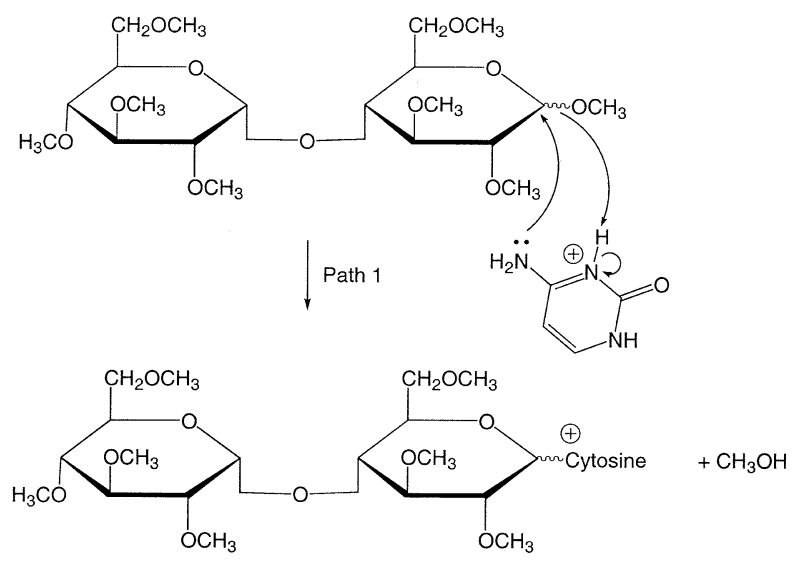

$\left[\mathrm{B}_{2}+\text { Cytosine }\right]^{+}$

(b)
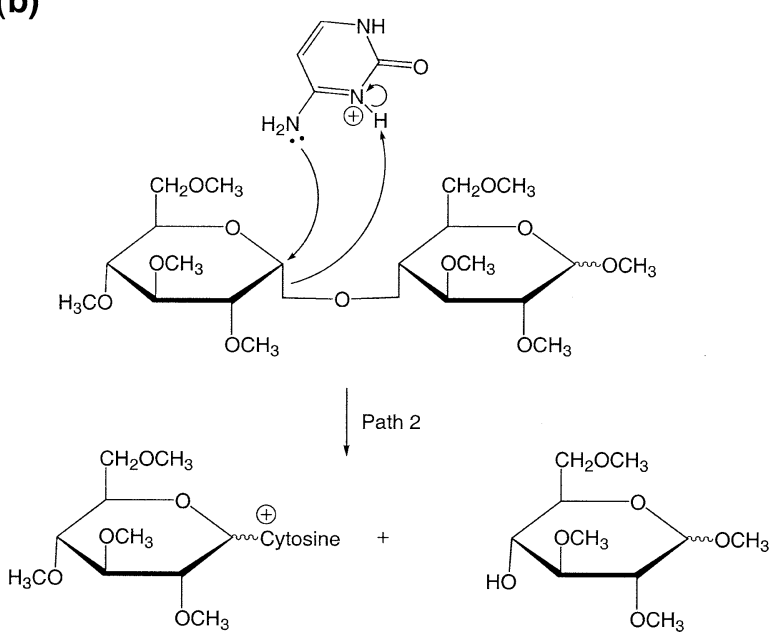

$\left[\mathrm{B}_{1}+\text { Cytosine }\right]^{+}$

Scheme 3

the ligand species and the fragmentation pathways of the native oligosaccharide-ligand complexes are not as clear cut as for the permethylated systems. For the [oligosaccharide + nucleobase $+\mathrm{H}]^{+}$complexes, $\left[\mathrm{B}_{\mathrm{x}}+\right.$ $\mathrm{L}^{+}$formation occurs only in some instances (Path 2A, Scheme 2). The majority of the other product ions formed are due to dissociation of the ligand species (Paths 1A, 1B, and 2B, Scheme 2).

In the case of the [oligosaccharide + nucleoside + $\mathrm{H}]^{+}$complexes, product ions corresponding to loss of the ligand are observed to be the major reaction pathway for many of the systems (Paths 1A, 1B, and 2B, Scheme 2). Cleavage of the ligand species however, does occur as a major fragmentation pathway in the larger systems containing deoxycytidine and deoxyguanosine (Path 3, Scheme 2). With regard to the [oligosaccharide + structurally related pyridine $+\mathrm{H}]^{+}$ complexes, they are generally observed to also result in loss of the ligand (Path 1A, 2B, Scheme 2).

Taking into consideration all of our findings thus far, there appear to be two main structural requirements for inducing fragmentation via Path 2A (Scheme 2), i.e., (1) a permethylated oligosaccharide; (2) a robust ligand species with multiple acidic and basic sites, particularly one with a $\mathrm{NH}_{2}$ group.

\section{Using Non-Covalent Complexes to Direct the Fragmentation of Glycosidic Bonds: Possible Mechanisms and Comparisons to the Condensed Phase Chemistry of Sugars}

In order to further illustrate our above observations regarding the structural requirements for inducing fragmentation via Path $2 \mathrm{~A}$ of Scheme 2, we have compiled the CID spectra of the [PMe-oligosaccharide-cytosine + $\mathrm{H}]^{+}$complexes (where oligosaccharide $=$PMe-maltotriose, PMe-maltotetraose, PMe-maltopentaose, PMemaltohexaose) in Figure 3. Irrespective of the size of the oligosaccharide, in all instances (Figure 1d, Figure 3) we can clearly see that the preferred fragmentation pathway of these non-covalent complexes involves cleavage of the oligosaccharide whilst retaining cytosine, i.e., $\left[\mathrm{B}_{\mathrm{x}}\right.$ + cytosine $^{+}$(Path 2A, Scheme 2). These reactions thus provide a "ladder series" of $\left[\mathrm{B}_{\mathrm{x}}+\right.$ cytosine ${ }^{+}$ions, which greatly simplifies the sequencing of these oligosaccharide. While "ladder series" have been generated by condensed phase acid hydrolysis for subsequent MS analysis [22], this approach is novel since it generates the "ladder series" in the gas phase.

What insights might the condensed phase chemistry of sugars offer into potential mechanisms for these novel gas phase glycosidic bond cleavage reactions? An examination of the literature reveals that several important classes of reactions of glycosides are catalyzed by species that provide acid and base sites. For example, enzymes that catalyze the hydrolysis of glycosidic bonds often involve a concerted attack of a enzymic nucleophile at the anomeric carbon coupled with protonation of the glycosidic oxygen by an acidic residue of the protein [23]. Epimerization of sugars can be catalyzed by bifunctional catalysts such as 2-hydroxypyridine, which offer acid and base catalysis in a concerted process [24]. Using these insights from condensed phase studies and the system [PMemaltose-cytosine $+\mathrm{H}]^{+}$as an example, a potential mechanism for our gas phase cleavage reaction is shown in Scheme 3. As cytosine is a robust species that possesses both acidic and basic sites, a concerted reaction may occur whereby cytosine becomes covalently bound to PMe-maltose as the glycosidic bond closest to the reducing end is broken (i.e., methanol loss) to yield the $\left[\mathrm{B}_{2}+\text { cytosine }\right]^{+}(\mathrm{m} / \mathrm{z} 534)$ ion (Figure 1d, Path 1 of Scheme 3a). Formation of the $\left[\mathrm{B}_{1}+\right.$ cytosine $^{+}$ion $(\mathrm{m} / \mathrm{z} 330)$ however, involves intermolecular proton transfer from cytosine to a different glycosidic bond that is subsequently cleaved coincidentally with nucleophilic attack by cytosine (Figure 1d, Path 2 of Scheme $3 \mathbf{b}$ ). 


\section{Conclusions}

The gas phase formation and chemistry of a number of permethylated and native non-covalent oligosaccharide-ligand complexes have been examined using ESI and tandem mass spectrometry. For the majority of the [PMe-oligosaccharide-ligand ${ }^{+}$complexes (where Ligand $=$ adenine, cytosine, guanine, 2-, 3-, and 4-aminopyridine), collision induced dissociation led to fragmentation via loss of a saccharide residue, whilst retaining the ligand species. This resulted in the formation of novel $\left[\mathrm{B}_{x}+\mathrm{L}^{+}\right.$ions (Path $2 \mathrm{~A}$, Scheme 2). The structural requirements for the formation of these $\left[\mathrm{B}_{\mathrm{X}}+\mathrm{L}\right]^{+}$ ions included the presence of a (1) permethylated oligosaccharide and (2) ligand containing multiple acidic and basic sites (particularly $\mathrm{NH}_{2}$ ). Cleavage of the ligand species occurred for those complexes containing nucleosides (Path 3, Scheme 2), while loss of the ligand species was observed for pyridine and 2-hydroxypyridine. For the native [Oligosaccharide-Ligand $]^{+}$complexes however, loss of the ligand species was one of the major reaction pathways for all of the complexes (Paths 1A and IB, Scheme 2). Further studies are underway to examine the general analytical utility of these ligand-directed cleavage reactions. In particular we are interested in determining whether gas phase "ladder series" of $\left[\mathrm{B}_{\mathrm{x}}+\mathrm{L}\right]^{+}$ions can be generated from other types of sugars such as branched sugars and glycoconjugates.

\section{Addendum}

After this manuscript was submitted, an excellent review of the mass spectrometry of sugars by Zaia has appeared which discusses various approaches to structurally characterize oligosaccharides via MS-based techniques [25].

\section{Acknowledgments}

AKV acknowledges the award of a Science Faculty Scholarship (Studentship). RAJO thanks the Australian Research Council for financial support (grant \#A29930202) and the University of Melbourne for funds to purchase the LCQ. The authors thank Dr. Spencer Williams for comments on the manuscript.

\section{References}

1. (a) Smith, R. D.; Bruce, J. E.; Wu, Q. Y.; Lei, Q. P. New Mass Spectrometric Methods for the Study of Noncovalent Associations of Biopolymers. Chem. Soc. Rev. 1997, 26, 191. (b) Daniel, J. M.; Friess, S. D.; Rajagopalan, S.; Wendt, S.; Zenobi, R. Quantitative Determination of Noncovalent Binding Interactions Using Soft Ionization Mass Spectrometry. Int. J. Mass Spectrom. 2002, 216, 1. (c) Beck, J. L.; Beck, M. L.; Colgrave, M. L.; Ralph, S. F.; Sheil, M. M. Electrospray Ionization Mass Spectrometry of Oligonucleotide Complexes with Drugs, Metals, and Proteins. Mass Spectrom. Rev. 2001, 20, 61.

2. (a) Schalley, C. A. Molecular Recognition and Supramolecular Chemistry in the Gas Phase. Mass Spectrom. Rev. 2001, 20, 253. (b) Schalley, C. A. Supramolecular Chemistry Goes Gas Phase:
The Mass Spectrometric Examination of Noncovalent Interactions in Host-Guest Chemistry and Molecular Recognition. Int. J. Mass Spectrom. 2000, 194, 11. (c) Lebrilla, C. B. The Gas-Phase Chemistry of Cyclodextrin Inclusion Complexes. Acc. Chem. Res. 2001, 34, 653. (d) O'Hair, R. A. J.; Vrkic, A. K. Molecular Recognition in the Gas Phase Ligand Switching Reactions of the Proton Bound Dimer of Sarcosine and Glycylglycine. Org. Biomol. Chem. 2003, 1, 745.

3. Schnier, P. D.; Klassen, J. S.; Strittmatter, E. E.; Williams, E. R. Activation Energies for Dissociation of Double Strand Oligonucleotide Anions: Evidence for Watson-Crick Base Pairing in Vacuo. J. Am. Chem. Soc. 1998, 120, 9605.

4. (a) Strittmatter, E. F.; Schnier, P. D.; Klassen, J. S.; Williams, E. R. Dissociation Energies of Deoxyribose Nucleotide Dimer Anions Measured Using Blackbody Infrared Radiative Dissociation. J. Am. Soc. Mass Spectrom. 1999, 10, 1095. (b) Vrkic, A. K.; O'Hair, R. A. J. Gas Phase Reactions of Trimethylborate with the $[\mathrm{M}-\mathrm{H}]^{-}$Ions of Nucleotides and Their NonCovalent Homo and Heterodimer Complexes. Aust. J. Chem. 2003, 56, 389. (c) Julian, R. R.; Beauchamp, J. L. Abiotic Synthesis of ATP from AMP in the Gas Phase: Implications for the Origin of Biologically Important Molecules from Small Molecular Clusters. Int. J. Mass Spectrom. 2003, 227, 147.

5. Vrkic, A. K.; O'Hair, R. A. J.; Lebrilla, C. B. Unusual Covalent Bond Breaking Reactions of $\beta$-Cyclodextrin Inclusion Complexes of Nucleobases/Nucleosides and Related Guest Molecules. Eur. J. Mass Spectrom. 2003, 9, 563.

6. Von Seggern, C. E.; Cotter, R. J. Fragmentation Studies of Noncovalent Sugar-Sugar Complexes by Infrared Atmospheric Pressure MALDI. J. Am. Soc. Mass Spectrom. 2003, 14, 1158.

7. Zhu, J.; Cole, R. B. Ranking of Gas-Phase Acidities and Chloride Affinities of Monosaccharides and Linkage Specificity in Collision-Induced Decompositions of Negative Ion Electrospray-Generated Chloride Adducts of Oligosaccharides. J. Am. Soc. Mass Spectrom. 2001, 12, 1193.

8. Ciucanu, I.; Kerek, F. A Simple and Rapid Method for the Permethylation of Carbohydrates. Carbohydr. Res. 1984, 131, 209.

9. Reid, G. E.; O' Hair, R. A. J.; Styles, M. L.; McFadyen, W. D.; Simpson, R. J. Gas-Phase Ion-Molecule Reactions in a Modified Ion Trap: H/D Exchange of Non-covalent Complexes and Coordinatively Unsaturated Platinum Complexes. Rapid Commun. Mass Spectrom. 1998, 12, 1701.

10. Roepstorff, P.; Fohlman, J. Proposal for a Common Nomenclature for Sequence Ions in Mass Spectra of Peptides. Biomed. Mass. Spectrom. 1984, 11, 601.

11. McLuckey, S. A.; van Berkel, G. J.; Glish, G. L. Tandem Mass-Spectrometry of Small, Multiply Charged Oligonucleotides. J. Am. Soc. Mass Spectrom. 1992, 3, 60.

12. Domon, B.; Costello, C. E. A Systematic Nomenclature for Carbohydrate Fragmentations in FAB-MS/MS Spectra of Glycoconjugates. Glycoconj. J. 1988, 5, 397.

13. (a) O'Hair, R. A. J. The Role of Nucleophile-Electrophile Interactions in the Unimolecular and Bimolecular Gas Phase Ion Chemistry of Peptides and Related Systems. J. Mass Spectrom. 2000, 35, 1377. (b) Bowie, J. H.; Brinkworth, C. S.; Dua, S. Collision-Induced Fragmentations of the $[\mathrm{M}-\mathrm{H}]^{-}$ Parent Anions of Underivatized Peptides. An Aid to Structure Determination and Some Unusual Negative Ion Cleavages. Mass Spec. Rev. 2002, 21, 87.

14. (a) Vrkic, A. K.; O'Hair, R. A. J.; Foote, S.; Reid, G. E. Fragmentation Reactions of All 64 Protonated Trimer Oligonucleotides and 16 Mixed Base Tetramer Oligonucleotides via Tandem Mass Spectrometry in an Ion Trap. Int. J. Mass Spectrom. 2000, 194, 145. (b) Vrkic, A. K.; O'Hair, R. A. J.; Foote, S. Fragmentation Reactions of All 64 Deprotonated Trimer 
Oligonucleotides and 16 Mixed Base Tetramer Oligonucleotides via Tandem Mass Spectrometry in an Ion Trap. Aust. J. Chem. 2000, 53, 307.

15. Reinhold, V. N.; Reinhold, B. B.; Chan, S. Carbohydrate Sequence Analysis by Electrospray Ionization Mass Spectrometry. Methods Enzymol. 1996, 271, 377.

16. Wee, S.; O'Hair, R. A. J.; McFadyen, W. D. Side Chain Radical Losses from Radical Cations Allows Distinction of Leucine and Isoleucine Residues in the Isomeric Peptides Gly-XXXArg. Rapid Commun. Mass Spectrom. 2002, 16, 884.

17. (a) Franz, A. H.; Lebrilla, C. B. Evidence for Long-Range Glycosyl Transfer Reactions in the Gas Phase. J. Am. Soc. Mass Spectrom. 2002, 13, 325. (b) Harvey, D. J.; Mattu, T. S.; Wormald, M. R.; Royle, L.; Dwek, R. A.; Rudd, P. M. "Internal Residue Loss": Rearrangements Occurring During the Fragmentation of Carbohydrates Derivatized at the Reducing Terminus. Anal. Chem. 2002, 74, 734.

18. Mendonca, S.; Cole, R. B.; Zhu, J. H.; Cai, Y.; French, A. D.; Johnson, G. P.; Laine, R. A. Incremented Alkyl Derivatives Enhance Collision Induced Glycosidic Bond Cleavage in Mass Spectrometry of Disaccharides. J. Am. Soc. Mass Spectrom. 2003, 14,63 .

19. (a) Cooks, R. G.; Patrick, J. S.; Kotiaho, T.; McLuckey, S. A. Thermochemical Determinations by the Kinetic Method. Mass Spectrom. Rev. 1994, 13, 287. (b) Cooks, R. G.; Koskinen, J. T.; Thomas, P. D. The Kinetic Method of Making Thermochemical Determinations. J. Mass Spectrom. 1999, 34, 85. (c) Armentrout,
P. B. Is the Kinetic Method a Thermodynamic Method? J. Mass Spectrom. 1999, 34, 74. (d) Armentrout, P. B. Entropy Measurements and the Kinetic Method: A Statistically Meaningful Approach. J. Am. Soc. Mass Spectrom. 2000, 11, 371. (e) Ervin, K. M. Microcanonical Analysis of the Kinetic Method. The Meaning of the "Apparent Entropy." J. Am. Soc. Mass Spectrom. 2002, 13, 435.

20. Cai, Y.; Cole, R. B. Stabilization of Anionic Adducts in Negative Ion Electrospray Mass Spectrometry. Anal. Chem. 2002, 74, 985.

21. Jebber, K. A.; Zhang, K.; Cassady, C. J.; Chung-Phillips, A. Ab Initio and Experimental Studies on the Protonation of Glucose in the Gas Phase. J. Am. Chem. Soc. 1996, 118, 10515.

22. Cancilla, M. T.; Gaucher, S. P.; Desaire, H.; Leary, J. A. Combined Partial Acid Hydrolysis and Electrospray Ionization-Mass Spectrometry for the Structural Determination of Oligosaccharides. Anal. Chem. 2000, 72, 2901.

23. Zechel, D. L.; Withers, S. G. Glycosidase Mechanisms: Anatomy of a Finely Tuned Catalyst. Acc. Chem. Res. 2000, 33, 11.

24. (a) Capon, B. Mechanism in Carbohydrate Chemistry. Chem. Rev. 1969, 69, 407. (b) Morpurgo, S.; Bossa, M. The Epimerisation of 2-Tetrahydropyranol Catalysed by the Tautomeric Couples 2-Pyridone/2-Hydroxypyridine and Formamide/ Formamidic Acid as a Model for the Sugar's Mutarotation: A Theoretical Study. Phys. Chem. Chem. Phys. 2003, 5, 1181.

25. Zaia, J. Mass Spectrometry of Oligosaccharides. Mass Spectrom. Rev. 2004, 23, 161. 